\title{
North American cost analysis of brand name versus generic drugs for the treatment of glaucoma
}

This article was published in the following Dove Press journal:

ClinicoEconomics and Outcomes Research

Monali S Malvankar-

Mehta $\mathbb{1}^{1,2}$

Lucy Feng ${ }^{3}$

Cindy ML Hutnik ${ }^{1,4}$

'Department of Ophthalmology, Schulich School of Medicine and Dentistry, The University of Western Ontario, London, Ontario N6A 4V2, Canada; ${ }^{2}$ Department of Epidemiology and Biostatistics, Schulich School of Medicine and

Dentistry, The University of Western Ontario, London, Ontario N6A 5Cl, Canada; ${ }^{3}$ School of Pharmacy, University of Waterloo, Kitchener, Ontario N2G 2B2, Canada; ${ }^{4}$ Department of Pathology, Schulich School of Medicine and

Dentistry, The University of Western Ontario, London, ON N6A 5CI, Canada

Correspondence: Monali S Malvankar-Mehta Department of Ophthalmology, St. Joseph's Hospital, 268 Grosvenor Street, London, Ontario N6A 4V2, Canada

Tel + I 5196858500 Ext 61288

$\mathrm{Fax}+15196613766$

Email Monali.Malvankar@schulich.uwo.ca
Background: According to the World Health Organization, glaucoma is a leading cause of irreversible blindness worldwide. By 2020, 80 million people will be affected by glaucoma in the world, which represents a significant financial burden to society. Glaucoma medications alone make up $38-52 \%$ of the total direct cost. The purpose of this research is to conduct a cost-minimization analysis to evaluate brand-name medications versus generic medications for treating glaucoma patients.

Methods: The per-bottle cost (in Canadian dollars) of brand-name drugs for glaucoma was obtained from the wholesaler, McKesson Canada, and, for generic drugs, from the Ontario Drug Benefit (ODB) Formulary. Further, a wastage adjustment fee, a pharmacy mark-up, and an ODB dispensing fee (\$CAD) was added to the cost of both brand and generic. Previously published frequencies of medication prescription were utilized to calculate the average annual cost for each class of brand and generic. For each medication class and for mono-, bi-, and tri-drug therapy, the cost differential between brands and generics over a six-year period was computed and analyzed from third-party payer perspective.

Results: In descending order, the average annual government-funded health care system costs were: combination drugs such as $\operatorname{Cosopt}^{\circledR}$ (\$748.23) were the most expensive, followed by prostaglandin analogs (\$246.36), carbonic anhydrase inhibitors (CAIs) (\$45.04), $\alpha$-agonist (\$30.34), $\beta$-blockers (\$29.29), and cholinergic agonists (\$16.51). Brand-name mono-drugs are $34 \%$ more expensive compared to generics. Brand-generic percentage cost differential for various medication classes over a six-year period was the highest for prostaglandin analogous $(44 \%)$, followed by $\beta$-blockers $(35 \%)$, $\alpha$-agonist $(31 \%)$, cholinergic agonists (22\%), combination drugs $(10 \%)$, and CAIs $(1 \%)$.

Conclusion: Brand-name drugs are relatively more expensive than their generic counterparts, with variable cost differentials depending on drug class.

Keywords: glaucoma, open-angle, cost analysis, generic drugs, branded drugs

\section{Background}

According to the World Health Organization, glaucoma is a leading cause of irreversible blindness worldwide, ${ }^{1,2}$ with 6.6 million bilaterally blind people. It has been estimated that at least 3 million people in the $\mathrm{US}^{3}$ and 400,000 people in Canada ${ }^{4}$ have been affected by glaucoma. By 2020, 80 million people will be affected by glaucoma in the world, ${ }^{4-6}$ which represents a significant financial burden to society. ${ }^{7}$ In the US, the total annual treatment cost for glaucoma patients is $\$ 2.86$ billion $^{3}$ and in Canada cost is $\$ 156$ million, which includes direct and indirect costs. ${ }^{6}$ The glaucoma medications alone make up $38-52 \%$ of the total direct cost. ${ }^{8}$

Brand-name medication refers to drugs that go through the rigor of Phases I-III clinical trials to ensure efficacy and safety, and the company that brings the drug to 
market is generally responsible for these research and development (R\&D) costs. The extensive data generated by the $R \& D$ process are essential to gaining subsequent government approval that will allow prescription of the drug. The company generally markets the drug using a proprietary name or "brand name" (Duramed Pharmaceuticals Inc., Diamox ${ }^{\circledR}$, Cincinnati, OH, USA, goes by the generic name acetazolamide), which has patent protection for a period. After the patent expires or is challenged, other companies (generic manufacturers) can start manufacturing the drug for sale, usually at a lower price. In some provinces in Canada, the government mandates a set percentage cost of generic medication relative to brand.

A generic is approved by the government for patient use if deemed "bioequivalent." According to Health Canada, for drugs administered orally, generic manufacturers can either repeat the chemistry, animal, or human studies (Phase I, II, and III clinical trials) already performed by a brand manufacturer or they can prove the value of their drug through comparative bioavailability (CB). ${ }^{9}$ In $\mathrm{CB}$ studies, both brand and generic are given to healthy human volunteers on two different occasions, and serum concentrations are measured for comparison. Generics are required to show the same amount and rate of delivery of the active ingredients as brands, ${ }^{9}$ and their efficacy is assessed by measuring the bioavailability in the volunteers' blood after oral use. Most generic manufacturers prefer to show $\mathrm{CB}$ data since safety and efficacy of the brand has already been proven and because $\mathrm{CB}$ data are less expensive and less time-intensive to gather. However, comparable testing for ophthalmic eye drops is not possible since it is difficult to measure absorption of the active ingredients in the eye.

Generic ophthalmic medications are required to contain the same active ingredients as the brand and with a predetermined acceptable concentration range, systemic absorption profile, and route of administration. However, the inactive ingredients - such as preservatives, antioxidants, thickening agents, buffers, and substances that adjust tonicity in generic compared to brand - may vary. Minor formulation differences in brand versus generic may affect how well active ingredients are absorbed in the eye. Second, changes in inactive ingredients can also affect the stability of the drug. ${ }^{10}$ Finally, in case of eye drops, the container in which the solutions and suspensions are placed and the color of the caps and packaging can also vary, ${ }^{11}$ and patients who rely upon color and/or style of the bottle may find it difficult to recognize the generic. Despite these concerns, generic drugs are widely used because of their cost benefit. ${ }^{12}$

Due to cost savings, about two-thirds of all drugs dispensed in the US are generic. ${ }^{13}$ For example, timolol maleate is a beta-blocker that lowers IOP by aqueous inflow suppression. Timoptic $\mathrm{XE}^{\circledR}(0.5 \%)$ (Merck \& Co., Whitehouse Station, NJ, USA), an American brand-name drug, is a gel formulation of timolol maleate. Timolol GFS $(0.5 \%)$ (Falcon Pharmaceuticals [Alcon], Fort Worth, TX, USA) is a generic version of Timoptic XE $(0.5 \%) .{ }^{11}$ Based on the clinical study by Schenker and Silver, ${ }^{14}$ Timolol GFS $(0.5 \%)$ was shown to be equally effective compared to Timoptic XE $(0.5 \%)$. However, the study by Mammo et $\mathrm{al}^{11}$ demonstrated significant differences between brand and generic in terms of volume, viscosity, and surface tension. In another study, DiamoxR was shown to be equally safe and effective compared to its generic counterpart. ${ }^{15}$ These data were possible since DiamoxR is an oral medication. In a cost-comparison study, the generic acetazolamide was shown to be $37 \%$ less expensive than the branded alternative. ${ }^{15}$ Additionally, given the cost of brand-name medications may significantly deter adherence. ${ }^{16}$

Various studies have considered the cost of either brand or generic for glaucoma. Vold et al evaluated the yearly cost of generics in the US, using the Scott and White prescription claims for 1484 patients. ${ }^{17}$ Fiscella et al conducted a controlled study to calculate the daily patient cost of various brands for glaucoma from the average wholesale price in the US. ${ }^{1}$ Rylander and Vold conducted a prospective study to calculate the yearly cost of generic. ${ }^{12}$ The theoretical yearly cost of generics for glaucoma was based on the average wholesale price and common dosing patterns. ${ }^{12}$ Schlenker et al conducted a cost comparison of US and Canadian glaucoma medications. ${ }^{18}$ Studies have yet to develop a cost-analysis model for comparing the cost of both generic and brand.

Lee and Hutnik performed a 6-year cost comparison of primary selective laser trabeculoplasty (SLT) with medical therapy in the treatment of open-angle glaucoma, ${ }^{19}$ the costs of brand were calculated using Lee and Hutnik study. Since cost represents a driving force for utilization, analysis and awareness of cost are becoming increasingly important as health care systems develop "cost-based" models of delivery.

Based on this rationale, a cost-minimization analysis of ophthalmic brand and generic in Ontario is presented from third-party payer perspective over a 6-year time horizon. 
Data such as these can provide a basis for studies in cost comparison and cost-effectiveness and may also be utilized by decision-makers and policy-makers to calculate the "cost to society" or "burden of the diseases." Costbased models of health care delivery will require an expanded awareness by clinicians, whose treatment decisions are likely already being affected by these comparative costs and their management.

\section{Materials and methods}

The direct costs (in Canadian dollars) of brand and generic were obtained from a wholesaler, McKesson Canada, and from the 2018 Ontario Drug Benefit (ODB) Formulary, ${ }^{20}$ respectively. While there are other pharmacy distributors, such as AmerisourceBergen Canada, McKesson Canada was chosen for use in this study since it is one of the largest independent pharmacy distributers. Sixteen McKesson distribution centers provide prescription drugs to more than 800 manufacturers, over 6500 pharmacies, 1300 hospitals, and to other health care institutions in Canada. ${ }^{11}$ The calculated daily cost for brand is listed in terms of amount per-package size, where package size represents the total volume in milliliters $(\mathrm{mL})$ per bottle. The ODB price for generic reflects the amount calculated per milliliter for single agents and the amount per package size for combination drugs.

Additional cost includes the wastage adjustment fee, Ontario pharmacy mark-up (8\%), and ODB dispensing fees. According to the ODB Act, the dispensing fee payable to most pharmacies is $\$ 9.93$ for each ODB prescription filled. On the other hand, the annual dispensing fee per bottle may vary, depending on the geographic location of the pharmacy. Also, pharmacies can waive or reduce the dispensing fee to attract more patients. For consistency, we calculated the annual dispensing fee per bottle as $\$ 9.93$. The annual ODB dispensing fee is regulated by the government for Ontario drug benefit payers, such as patients who are 65 years of age or older, residents of long-term care homes, residents of the Homes for Special Care Program, people receiving professional services under the Home Care program, and Trillium drug program registrants. However, if the patient is not an ODB patient and they are privately insured or uninsured, then dispensing fees may vary, depending on the type of private drug plan and the amount of the deductible to the patient. In general, for uninsured patients, pharmacy mark-up and the ODB dispensing fee may be mandated by the pharmacy.

Commonly prescribed anti-glaucoma eye drops in both branded and generic formulations were included in this study. We grouped all the medications into six major classes: carbonic anhydrase inhibitors (CAIs), $\alpha$-agonists, prostaglandin analogs, $\beta$-blockers, cholinergic agonists, and combination drugs. ${ }^{21}$ Table 1 lists the details of the medications in each major class.

Data on volume per bottle were obtained from Iordanous et al. ${ }^{22}$ Contemporary medications, as well as older formulations, are sometimes absent from published cost analyses, due primarily to their unavailability at the time of publication. ${ }^{19}$ In this study, the lack of published data required the following assumptions to be made: Pilopine $\mathrm{Hs}^{\circledR}$ gel had a $5 \mathrm{~mL}$ package size, which was like Isopto carpine $2 \%$. Thus, volume per bottle for Pilopine Hs gel was assumed to be $5 \mathrm{~mL}$. Similar assumptions were made for Isopto carpine $1 \%$ of which had a package size like Isopto carpine 2\%. For Alphagan PR and Betoptic $S^{\circledR}$, the values on volume per bottle were obtained from Iordanous et al. ${ }^{22}$ ODB formulary was searched to obtain data on volume per bottle for combination and newer medications and Lumigan $\mathrm{RC}^{\circledR}$.

The values of drops per milliliter and dose per day in both eyes (OU) were obtained from the literature. ${ }^{1,19,22}$ In cases where this value was unknown, values of drops per milliliter and drops per day OU within the class were assumed to be similar. Additionally, no patient data were collected; thus, ethics approval was deemed unnecessary.

Pharmacy fees in Ontario, including an 8\% markup $\mathrm{fee}^{23}$ and a $\$ 9.93$ annual dispensing fee per bottle, ${ }^{21}$ were added to the annual cost of the medication class to obtain the average annual cost to Ontario Health Insurance Plan (OHIP). A detailed equation appears below:

Average annual cost of the medication class to OHIP =

Average cost of the medication class

+ Annual dispensing fee $(\$ 8.83)$

$+\left(\begin{array}{l}\text { Average cost of the medication class } \\ \times \text { Pharmacy markup }(0.08)\end{array}\right)$

The empirical number of bottles used annually per medication was obtained from Iordanous et al, ${ }^{22}$ which accounted for misadministration of medication by patient and for patient non-compliance. Empirical refill rates for dorzolamide-timolol, brimonidine, travoprost, latanoprost, timolol-XE, dorzolamide, brinzolamide, timolol, levobunolol, and pilocarpine were obtained from Lee and Hutnik $^{19}$ and from Iordanous et al. ${ }^{22}$

Glaucoma medication utilization patterns were obtained from the literature ${ }^{22}$ Table 2 lists these utility rates by class. The utilization rate or frequency of a medication class prescribed was used to determine the average 
Table I Annual cost data from Mckesson Canada Inc. of glaucoma medications by class of drug

\begin{tabular}{|c|c|c|c|c|c|c|c|c|c|c|}
\hline $\begin{array}{l}\text { Brand name } \\
\text { drug }\end{array}$ & $\begin{array}{l}\text { Cost } \\
(\$ / P k)\end{array}$ & $\begin{array}{l}\text { Volumel } \\
\text { bottle } \\
(\mathrm{mL})\end{array}$ & $\begin{array}{l}\text { Drops/ } \\
\mathrm{mL}\end{array}$ & $\begin{array}{l}\text { Drops/ } \\
\text { bottle }\end{array}$ & $\begin{array}{l}\text { Dosel } \\
\text { day } \\
\text { (OU) }\end{array}$ & $\begin{array}{l}\text { Theor. } \\
\text { days/ } \\
\text { bottle }\end{array}$ & $\begin{array}{l}\text { Bottles/ } \\
\text { year }\end{array}$ & $\begin{array}{l}\text { Cost/ } \\
\text { year } \\
(\$)\end{array}$ & $\begin{array}{l}\text { Waste } \\
\text { adjustment }\end{array}$ & $\begin{array}{l}\text { Pharm. adj } \\
\text { costs/year } \\
\text { (\$) }\end{array}$ \\
\hline \multicolumn{11}{|c|}{ a) Combination drugs } \\
\hline Cosopt & 62.95 & 10.9 & 25.9 & 282.31 & 4 & 70.58 & 5.17 & 354.85 & 2.14 & 758.93 \\
\hline \multicolumn{8}{|l|}{ Average cost } & 354.85 & & 758.93 \\
\hline \multicolumn{8}{|c|}{ Avg annual cost to OHIP } & 391.64 & & 828.04 \\
\hline \multicolumn{11}{|c|}{ b) Carbonic anhydrase inhibitors (CAls) } \\
\hline Trusopt & 20.16 & 5.4 & 25.7 & 138.78 & 5 & 27.76 & 13.15 & 53.02 & 1.65 & 37.06 \\
\hline Azopt & $|7.3|$ & 5 & 24.6 & 123 & 5 & 24.60 & 14.84 & 51.37 & 1.65 & 31.82 \\
\hline \multicolumn{8}{|l|}{ Average cost } & 52.19 & & 34.44 \\
\hline \multicolumn{8}{|c|}{ Avg annual cost to OHIP } & 64.77 & & 45.59 \\
\hline \multicolumn{11}{|c|}{ c) $\alpha$-agonists covered by OHIP } \\
\hline Alphagan P & 12.42 & 5.4 & 21.1 & 113.94 & 4 & 28.49 & $12.8 \mid$ & 31.83 & 0.89 & 28.33 \\
\hline Alphagan & 17.74 & 5.4 & 21.1 & 113.94 & 4 & 28.49 & 12.81 & 45.46 & & 32.61 \\
\hline \multicolumn{8}{|l|}{ Average cost } & 38.65 & & 30.47 \\
\hline \multicolumn{8}{|c|}{ Avg annual cost to OHIP } & 50.14 & & 41.31 \\
\hline \multicolumn{11}{|c|}{ d) Prostaglandin analogs } \\
\hline Travatan & 58.14 & 5.4 & 34 & 183.6 & 2 & 91.80 & 3.98 & 249.66 & 2.35 & 587.66 \\
\hline Xalatan & 29.07 & 3.05 & 32 & 97.6 & 2 & 48.80 & 7.48 & 265.26 & 1.25 & 331.92 \\
\hline Lumigan RC & 34.88 & 3.3 & 37.4 & 123.42 & 2 & 61.71 & 5.91 & 226.94 & 1.55 & 352.63 \\
\hline \multicolumn{8}{|l|}{ Average cost } & 202.66 & & 350.20 \\
\hline \multicolumn{8}{|c|}{ Avg annual cost to OHIP } & 227.27 & & 386.62 \\
\hline \multicolumn{11}{|l|}{ e) $\beta$-blockers } \\
\hline Timolol & 29.73 & 10.9 & 32.6 & 355.34 & 4 & 88.84 & 4.11 & 12.22 & 1.65 & 27.32 \\
\hline Timolol & 36.99 & 10.9 & 32.6 & 355.34 & 4 & 88.84 & 4.11 & 15.20 & 1.65 & 34.00 \\
\hline Timoptic-XE & 19.91 & 6 & 26.1 & 156.6 & 2 & 78.30 & 4.66 & 18.56 & 1.54 & 28.50 \\
\hline Timoptic-XE & 23.83 & 6 & 26.1 & 156.6 & 2 & 78.30 & 4.66 & 22.22 & 1.54 & 34.11 \\
\hline Betoptic S & 23.96 & 5.2 & 29.4 & 152.88 & 4 & 38.22 & 9.55 & 45.76 & 0.96 & 44.04 \\
\hline Betagan & 17.69 & 10.2 & 21.1 & 215.22 & 4 & 53.81 & 6.78 & 12.00 & 1.35 & 16.26 \\
\hline \multicolumn{8}{|l|}{ Average cost } & 20.99 & & 30.70 \\
\hline \multicolumn{8}{|c|}{ Avg annual cost to OHIP } & 31.07 & & 41.56 \\
\hline \multicolumn{11}{|c|}{ f) Cholinergic agonists } \\
\hline Pilopine Hs gel & 13.43 & 5 & 25 & 125 & 4 & 31.25 & 11.68 & 31.37 & 1.65 & 24.69 \\
\hline Isopto carpine I\% & 3.25 & 5 & 25 & 125 & 4 & 31.25 & 11.68 & 7.59 & 1.65 & 5.97 \\
\hline Isopto carpine $2 \%$ & 3.75 & 5 & 25 & 125 & 4 & 31.25 & 11.68 & 8.76 & 1.65 & 6.89 \\
\hline Isopto carpine $4 \%$ & 4.24 & 5 & 25 & 125 & 4 & 31.25 & 11.68 & 9.90 & 1.65 & 7.79 \\
\hline \multicolumn{8}{|l|}{ Average cost } & $|4.4|$ & & 11.34 \\
\hline \multicolumn{8}{|c|}{ Avg annual cost to OHIP } & 23.96 & & 20.64 \\
\hline
\end{tabular}


Table 2 Utility rates for various medications class

\begin{tabular}{|l|l|l|l|l|l|l|}
\hline \multirow{2}{*}{ Therapy } & \multicolumn{4}{l|}{ No. of prescriptions (\%) } \\
\cline { 2 - 7 } & Combination drugs & CAls & a-Agonists & Prostaglandin & \multicolumn{1}{l|}{$\beta$-blockers } & Cholinergic agonists \\
\hline Mono-drug therapy & $38(9)$ & $2(0)$ & $13(3)$ & $22 I(54)$ & $126(31)$ & $7(2)$ \\
Bi-drug therapy & $84(18)$ & $27(6)$ & $39(8)$ & $203(42)$ & $114(24)$ & $16(3)$ \\
Tri-drug therapy & $23(12)$ & $22(12)$ & $44(24)$ & $57(31)$ & $27(15)$ & $14(7)$ \\
Total occurrences of drug & $145(14)$ & $51(5)$ & $96(9)$ & $48 I(45)$ & $267(25)$ & $37(2)$ \\
\hline
\end{tabular}

Notes: Adapted with permission from Lee R, Hutnik CML. Projected cost comparison of selective laser trabeculoplasty versus glaucoma medication in the Ontario Health Insurance Plan. Can J Ophthalmol. 2006;4I(4):449-456. doi:I0.10I6/S0008-4I82(06)80006-2A. ${ }^{19}$ Adapted from lordanous Y, Kent JS, Hutnik CML, MalvankarMehta MS. Projected cost comparison of trabectome, iStent, and endoscopic cyclophotocoagulation versus glaucoma medication in the Ontario Health Insurance Plan. J Glaucoma. 2014;23(2):el I2-el I8. doi: 10.1097/JjG.0b0I3e31829d9bc7. Copyright @ 2014, @ 2014 by Lippincott Williams. ${ }^{22}$

annual cost of all glaucoma medications in Ontario. ${ }^{22}$ Table 3 lists the frequency of mono-, bi-, and tri-drug therapies for glaucoma patients in Ontario. Based on the literature, ${ }^{24}$ safety and efficacy of the generic drug was assumed to be similar to brand-name drug.

\section{Results}

The average annual OHIP cost for each medication class of the brand is shown in Table 1 and of the generic in Table 4. For the various medication classes, the average annual OHIP cost per patient is shown in Figure 1. Combination drugs were the most expensive (\$748.23), followed by prostaglandin analogs (\$246.36), CAIs (\$45.04), $\alpha$-agonists (\$30.34), $\beta$-blockers (\$29.29), and cholinergic agonists (\$16.51).

Brand-name drugs were found to be more expensive than their respective generic alternatives. The cost differential between the branded and generic medications for mono-, bi-, and tri-drug therapy for over a 6-year period is shown in Figure 2. The graph in Figure 2 suggests that, over a 6-year period, branded bi-drug therapy is more expensive compared to generic tri-drug therapy. Also, over a 6-year period, the branded tri-drug cost is

Table 3 Frequency of mono-, bi-, and tri-drug therapies for treatment of glaucoma in Ontario

\begin{tabular}{|l|l|}
\hline & No. of patients (\%) \\
\hline Mono-drug therapy & $407(57.6)$ \\
Bi-drug therapy & $239(33.8)$ \\
Tri-drug therapy & $61(8.6)$ \\
Total number of patients & $707(100)$ \\
\hline
\end{tabular}

Note: Adapted with permission from Lee R, Hutnik CML. Projected cost comparison of selective laser trabeculoplastyversus glaucoma medication in the Ontario Health InsurancePlan. Can J Ophthalmol. 2006;4I(4):449-456. doi:I0.1016/S0008-4I82(06) 80006-2A. ${ }^{19}$ Adapted from lordanous Y, Kent JS, Hutnik CM, MalvankarMehta MS. Projected cost comparison of trabectome, iStent, and endoscopic cyclophotocoagulation versus glaucoma medication in the Ontario Health Insurance Plan. $J$ Glaucoma. 2014;23(2):el I2-8. doi: 10.1097/JG.0b013e31829d9bc7. Copyright () 2014, (C) 2014 by Lippincott Williams. ${ }^{22}$ approximately $\$ 1000$ more than a generic tri-drug, while the branded bi-drug cost is approximately $\$ 900$ more than a generic bi-drug, and the branded mono-drug cost is approximately $\$ 500$ more than a generic mono-drug.

Brand-generic percentage cost differential is shown in Figure 3 for mono-, bi-, and tri-drug therapy for over 6 years. Brand-name mono-drugs are 34\% high-priced compared to their generic counterparts over 6 years. Brandname bi- and tri-drugs are $27 \%$ costly compared to generics. The difference between brands and generics cost for the various medication classes is shown in Figure 4. The greatest difference exists between generic and branded prostaglandin analogous (\$841.55), followed by combination drugs (\$478.90), $\beta$-blockers (\$73.60), $\alpha$-agonist (\$65.84), cholinergic agonists (\$24.78), and CAIs (\$3.34). Generic prostaglandin costs $\$ 841.55$ less than branded prostaglandin. These lower costs create a strong incentive for switching patients to a generic prostaglandin, also in addition to creating a more competitive generic market for this class of anti-glaucoma medication. Moreover, efficacy of the generic drug, stability in the bottle, bottle design/composition, and side effects do not factor into this switch.

Figure 5 shows the percentage difference between brand and generic for various medication classes over 6 years. Brand-name prostaglandins are $44 \%$ pricey compared to generic equivalents followed by $\beta$-blockers (35\%), $\alpha$-agonist (31\%), cholinergic agonists (22\%), combination drugs (10\%), and CAIs (1\%). Prostaglandins are first line of treatment and $\beta$-blockers are the second line of treatment for primary open-angle glaucoma patients. Lowincome families are enticed to switch to generic equivalents of prostaglandins and $\beta$-blockers given the cost.

\section{Discussion}

In this cost analysis study, brand-name drugs were shown to be high-priced than generic drugs, but the cost savings were 


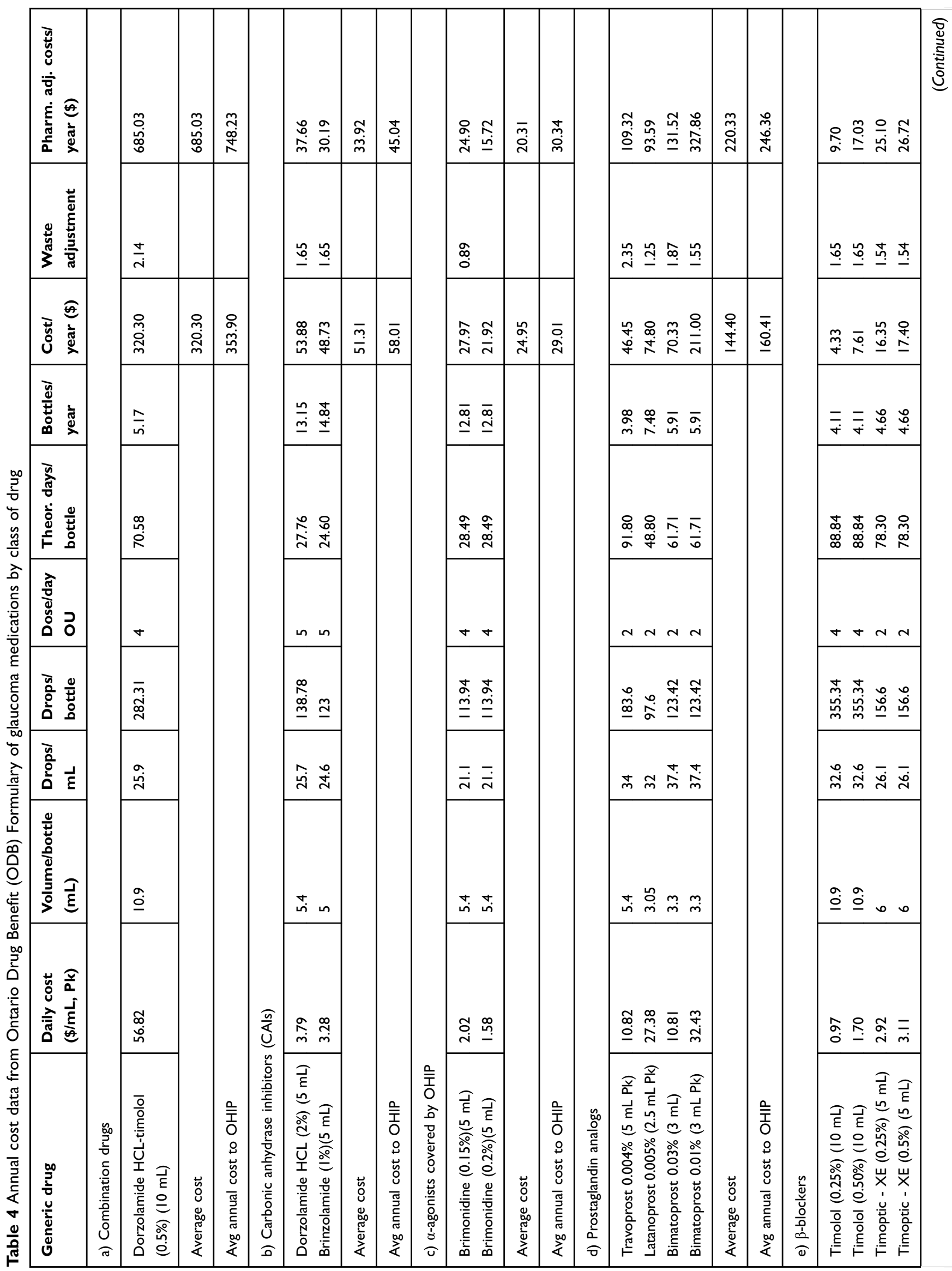




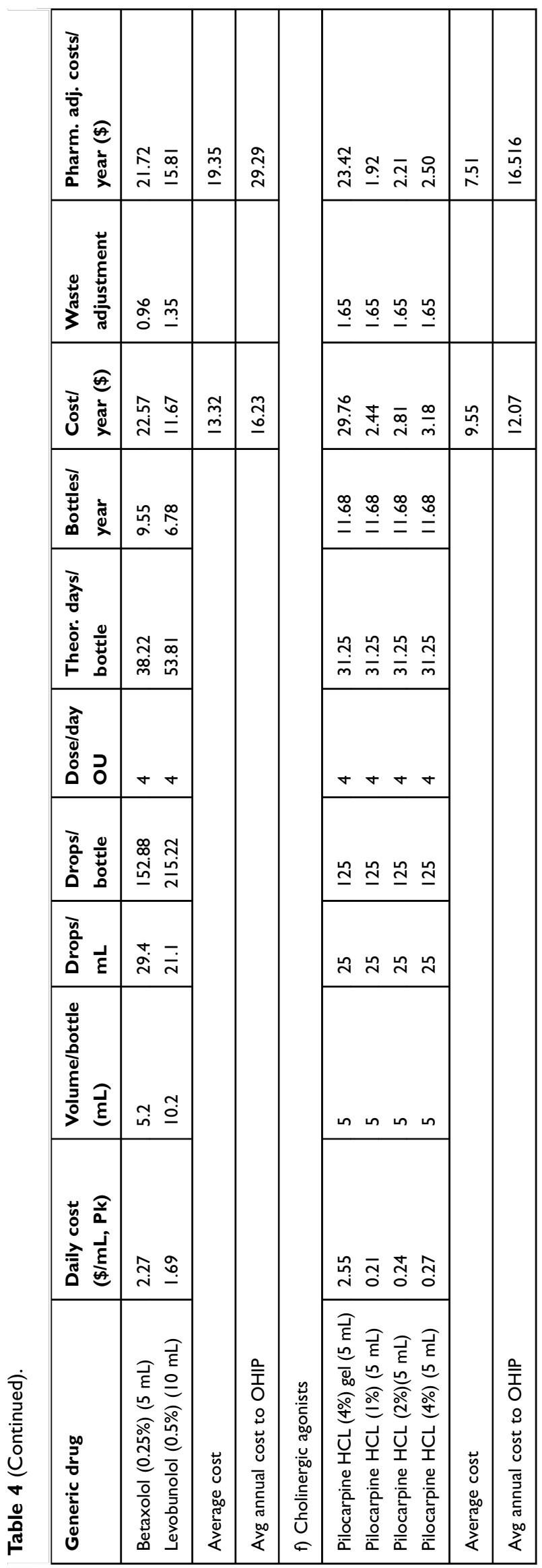

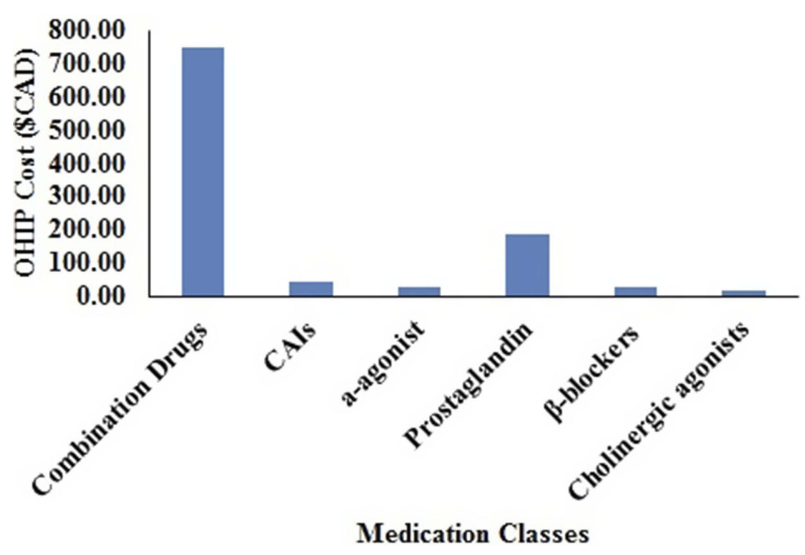

Figure I Average annual OHIP cost by medication class.

inconsistent among the classes. Since first-line agents have the lowest generic costs, the profits may be linked to volume of sales. Despite government reform that mandated a set generic price on a percentage basis, cost differences were highly variable, depending on the drug class. The cost difference between brands and generics may be less significant if therapy is short term and of low prevalence. However, for chronic diseases that are prevalent, such as glaucoma, the cost differences become significant over time.

It was not the intent of this study to include indirect costs, such as the quality-of-life costs associated with eyedrop toxicity, allergies, and/or noncompliance. Unlike a cost-effective analysis, this study did not address the costs of treatment success or failure. Rather, the intent here was to produce a study that could be used as a foundation for more extensive economic analyses that include indirect costs and the influences of treatment outcomes. Importantly, this research represents a contemporary cost-minimization analysis study as glaucoma medications transition into the generic market, and it creates awareness of the actual cost differential between antiglaucoma brands and generics.

A product's life cycle involving five stages: development, introduction, growth, maturity, and decline may apply to brand-name and generic drugs. ${ }^{25}$ In the introduction stage, sales are low, prices are high for the manufacturer to recoup development costs. In the growth stage, sales increase and prices are generally maintained at a high level. Maturity stage is the most profitable stage when sales increase. During the decline stage, prices may fall to liquidate inventory. However, competition may decrease the market share and/or prices. Patent expiry is an important milestone in the life cycle of brands. ${ }^{26}$ Generics are introduced when 


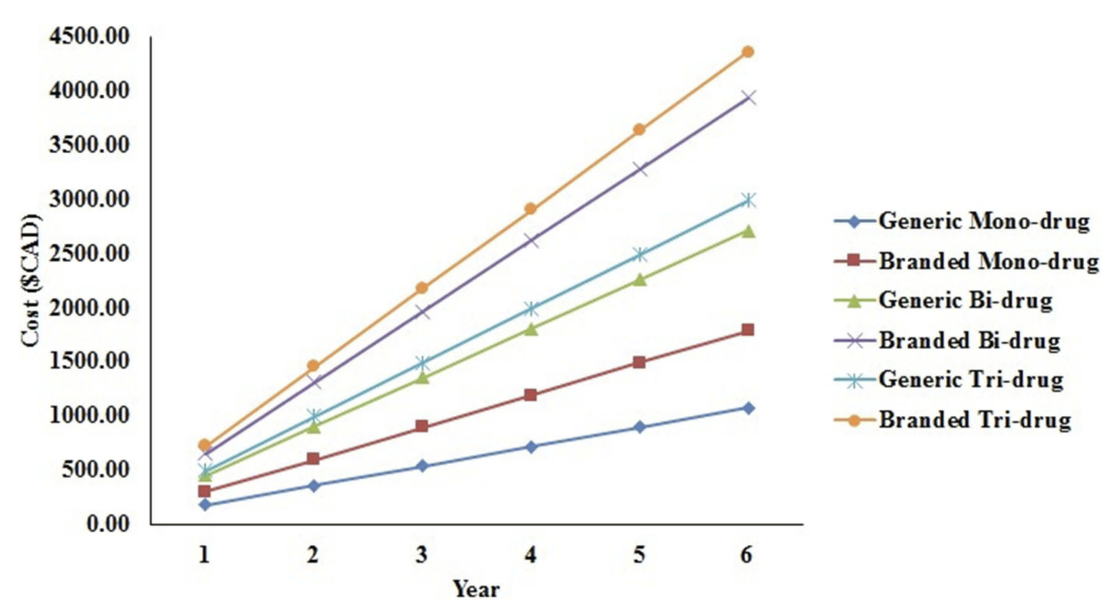

Figure 2 Difference between branded and generic medications for mono-, bi-, and tri-drug therapy for over 6 years.

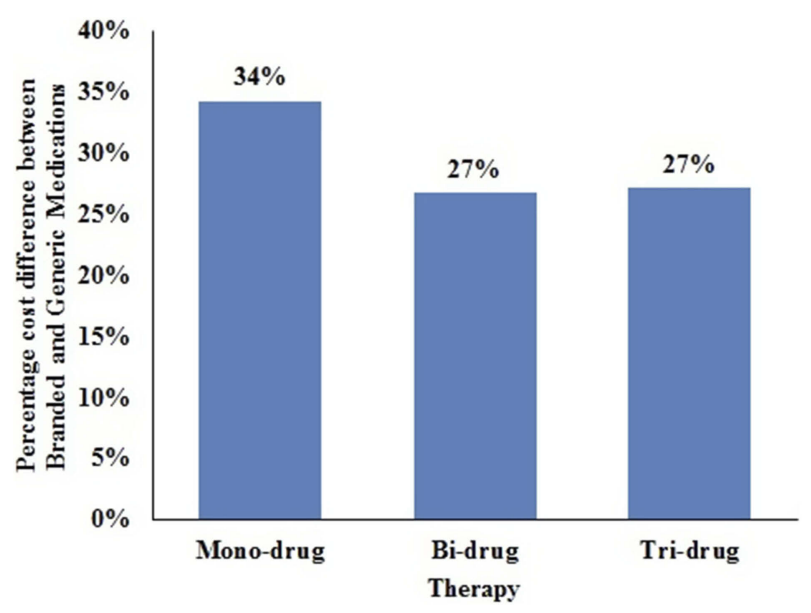

Figure 3 Percentage difference between branded and generic medications for mono-, bi-, and tri-drug therapy for over 6 years.

brand patent expires. Brand manufactures may reduce production, drop price, or may phase out due to low profits. Thus, timewise, generics could be analyzed separately then brands. However, data show the demand elasticity of generics is relatively independent of time. ${ }^{26}$ Further, customers may choose brands over generics to ensure safety and efficacy irrespective of price. This study, based on the literature ${ }^{24}$ assumed similarity in efficacy or safety of GM compared to BM. A review of the literature revealed that very few studies have been conducted in this regard. Thus, computing Quality Adjusted Life Years (QALYs) due to generic compared to brand may represent a natural extension of this study.

Additionally, the prices presented of brands and generics may get influenced by the current stage of their product life cycles. However, there are limitations to the product life cycle concept. Life cycle curves vary substantially by brands and generics. ${ }^{25}$ Second, manufactures differ so not all brands and generics go through every stage of product life cycle. Even if they go through every stage of product life cycle, length of time spent in each stage may vary with drugs. ${ }^{27}$ Third, it is difficult to see transitions in product life cycle phases. Fourth, market conditions or consumer tastes may change dynamically adding uncertainty to the product life cycle. Fifth, a product life cycle may be an unreliable indicator of the product's true-life span.

The information presented in the study is highly relevant during an era when cost represents a predominant factor in health care decision making. The costminimization analysis performed herein may be helpful to clinicians, hospital administrators, payers and policy-makers in their decision-making efforts since cost will have to be balanced with therapeutic efficacy and safety. Further, switching to generics may help improve patients' adherence. ${ }^{16}$

\section{Conclusion}

If the brand-generic cost differential is large and the generics prove to be comparable in safety and efficacy, then all levels of the health-care system may embrace the movement to generics. However, if the generic is less tolerable and/or less efficacious, clinicians may need to challenge the cost-based approach to ensure maximum patient outcomes. Similarly, if the brand-generic cost differential is relatively small, clinicians may choose not to gamble on potential problems with the switch to generic. The small differential may not be worth the risk is highlighted by our study's finding that a significant cost differential does exist between generic and brand for 


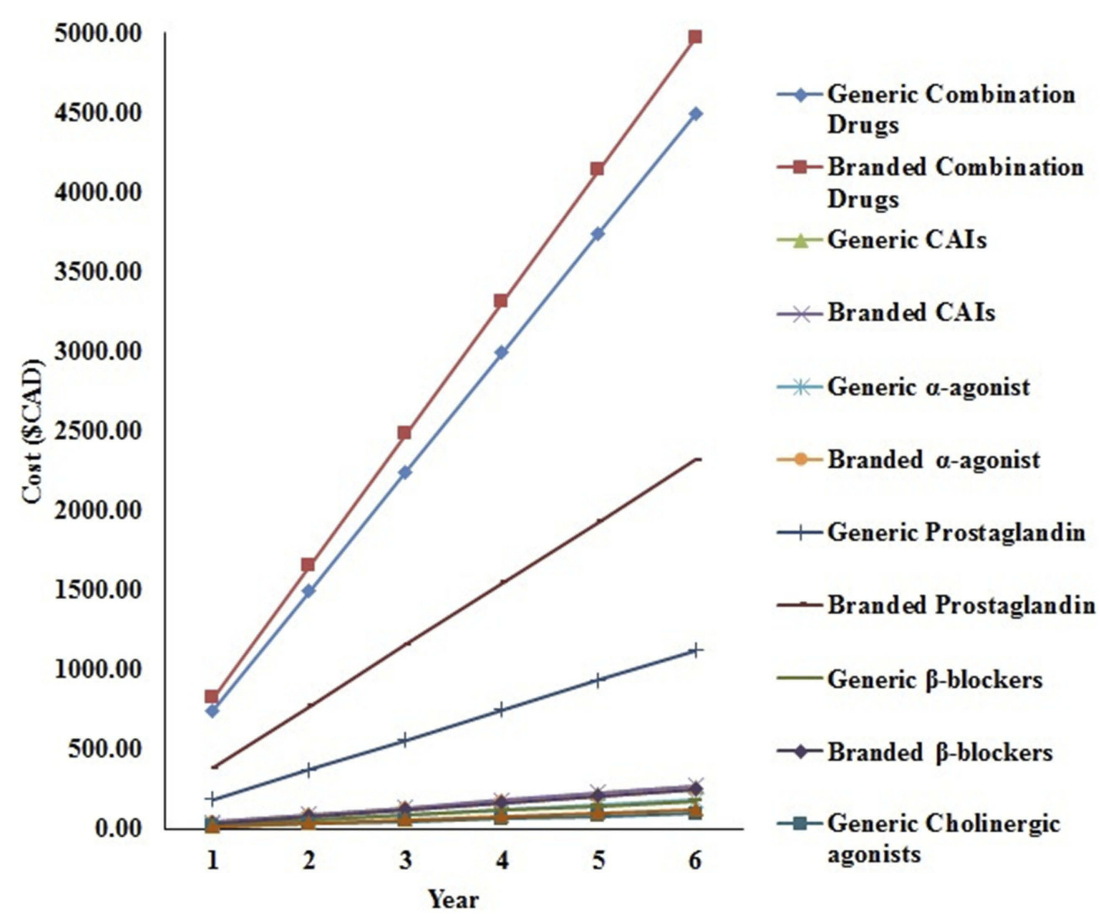

Figure 4 Difference between branded and generic medications for various medication classes over 6 years.

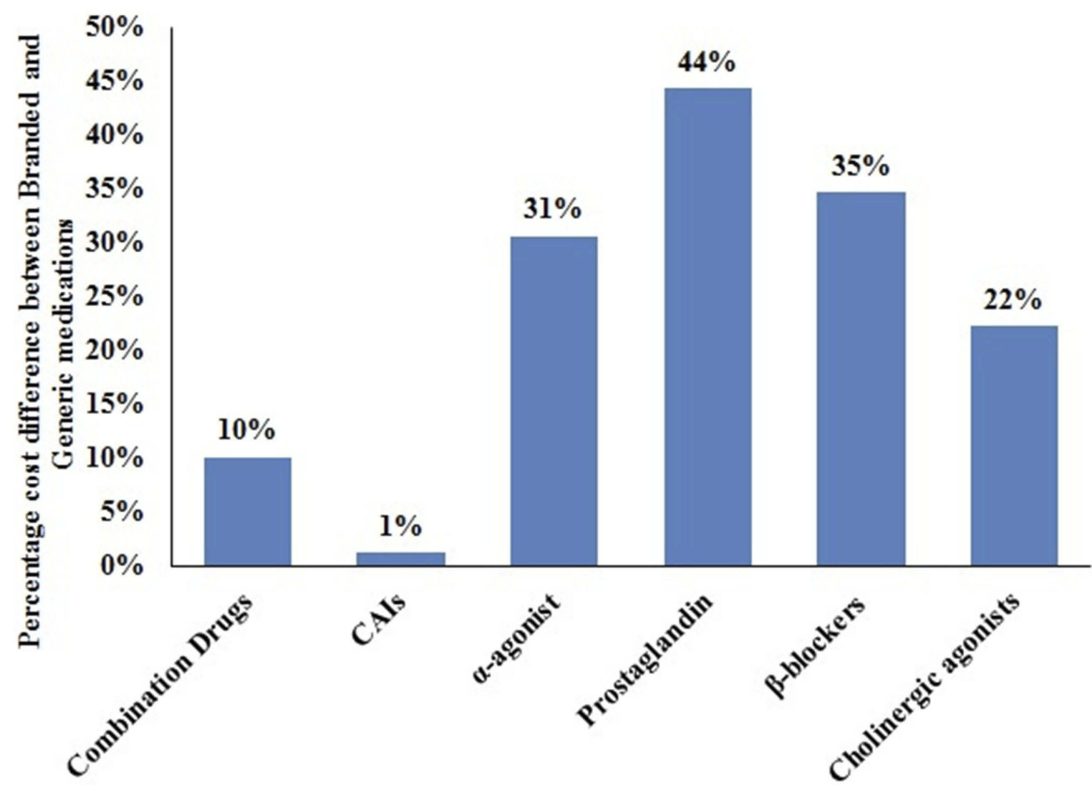

Medication Class

Figure 5 Percentage difference between branded and generic medications for various medication classes for over 6 years.

prostaglandin and combination glaucoma eye drops. Clinicians must be vigilant in monitoring safety and efficacy, especially for these classes, which are frequently used in the management of glaucoma. Further, clinicians must acknowledge that the historical comfort level associated with these brands may not be assumed, especially when cost represents the driving factor for utilization.

\section{Abbreviations}

ODB, Ontario Drug benefit formulary; R\&D, research and development; CB, comparative bioavailability; IOP, intraocular pressure; OHIP, Ontario Health Insurance Plan; CAI, carbonic anhydrase inhibitors; SLT, selective laser trabeculoplasty; OU, oculus uterque (both eyes); QALYs, Quality Adjusted Life Years; NGOs, non-governmental organizations. 


\section{Ethics approval and consent to participate}

No human subjects were recruited for the study; hence ethics approval was deemed unnecessary.

\section{Availability of data and materials}

All data is presented within the manuscript.

\section{Author contributions}

All authors contributed to data analysis, drafting or revising the article, gave final approval of the version to be published, and agree to be accountable for all aspects of the work.

\section{Disclosure}

The authors report no conflicts of interest in this work.

\section{References}

1. Fiscella RG, Green A, Patuszynski DH, Wilensky J. Medical therapy cost considerations for glaucoma. Am J Ophthalmol. 2003;136(1):1825. doi:10.1016/s0002-9394(03)00102-8

2. Kingman S. Glaucoma Is Second Leading Cause of Blindness Globally. World Health Organization; 2004.

3. Foundation BF. Glaucoma: facts \& figures. Bright Focus Foundation; 2017. Available from: http://www.brightfocus.org/glaucoma/article/ glaucoma-facts-figures. Accessed March 24, 2016.

4. Glaucoma Research Society of Canada. Quick facts; 2018. Available from: https://www.glaucomaresearch.ca/about/about-glaucoma/. Accessed May 31, 2018.

5. Quigley HA, Broman AT. The number of people with glaucoma worldwide in 2010 and 2020. Br J Ophthalmol. 2006;90(3):262267. doi:10.1136/bjo.2005.081224

6. MEDEC's Ophthalmic Sector Committee. Economic benefits of treatment. MEDEC; 2018. Available from: http://www.medec.org/ webfm_send/434. Accessed March 21, 2018.

7. Varma R, Lee PP, Goldberg I, Kotak S. An assessment of the health and economic burdens of glaucoma. Am J Ophthalmol. 2011;152 (4):515-522. doi:10.1016/j.ajo.2011.06.004

8. Lee PP, Walt JG, Doyle JJ, et al. A multicenter, retrospective pilot study of resource use and costs associated with severity of disease in glaucoma. Arch Ophthalmol. 2006;124(1):12. doi:10.1001/archopht.124.1.12

9. Health Canada. The safety and effectiveness of generic drugs; 2012. Available from: https://www.canada.ca/en/health-canada/services/ healthy-living/your-health/medical-information/safety-effectivenessgeneric-drugs.html. Accessed March 21, 2018.

10. Kahook MY, Fechtner RD, Katz LJ, Noecker RJ, Ammar DA. A comparison of active ingredients and preservatives between brand name and generic topical glaucoma medications using liquid chromatography-tandem mass spectrometry. Curr Eye Res. 2012;37:1-8.
11. Mammo ZN, Flanagan JG, James DF, Trope GE. Generic versus brand-name North American topical glaucoma drops. Can J Ophthalmol. 2012;47(1):55-61. doi:10.1016/j.jcjo.2011.12.004

12. Rylander NR, Vold SD. Cost analysis of glaucoma medications. Am J Ophthalmol. 2008;145(1):106-113. doi:10.1016/j.ajo.2007.08.041

13. Haas JS, Phillips KA, Gerstenberger EP, Seger AC. Potential savings from substituting generic drugs for brand-name drugs: medical expenditure panel survey, 1997âe“2000. Ann Intern Med. 2005;142 (11):891-897. doi:10.7326/0003-4819-142-11-200506070-00006

14. Schenker HI, Silver LH. Long-term intraocular pressure lowering efficacy and safety of timolol maleate gel-forming solution $0.5 \%$ compared with timoptic XE $0.5 \%$ in a 12 -month study. Am J Ophthalmol. 2000;130(2):145-150. doi:10.1016/s0002-9394(00)00458-x

15. Gallardo MJ, Fiscella RG, Whitson JT. Generic Glaucoma Medications. Is It Safe to Switch? 2006.

16. Stein JD, Shekhawat N, Talwar N, Balkrishnan R. Impact of the introduction of generic latanoprost on glaucoma medication adherence. Ophthalmology. 2015;122(4):738-747. doi:10.1016/j.ophtha.2014.11.022

17. Vold SD, Riggs WL, Jackimiec J. Cost analysis of glaucoma medications: a 3-year review. J Glaucoma. 2002;11(4):354-358.

18. Schlenker MB, Trope GE, Buys YM. Comparison of United States and Canadian glaucoma medication costs and price change from 2006 to 2013. J Ophthalmol. 2015;2015.

19. Lee R, Hutnik CML. Projected cost comparison of selective laser trabeculoplasty versus glaucoma medication in the Ontario Health Insurance Plan. Can J Ophthalmol. 20;41(4):449-456. doi:10.1016/S0008-4182(06) 80006-2

20. Ontario Drug Benefit (ODB) Formulary. Drugs and Devices Division; 2018. Available from: http://www.health.gov.on.ca/en/pro/ programs/drugs/odbf_mn.aspx. Accessed January 19, 2018.

21. Ministry of Health and Long-term Care O, Canada. Ontario drug benefit program: dispensing fees. Ministry of Health and Long-term Care; 2019. Available from: http://www.health.gov.on.ca/en/public/ programs/drugs/programs/odb/opdp_dispensing_fees.aspx. Accessed May 31, 2019.

22. Iordanous Y, Kent JS, Hutnik CM, Malvankar-Mehta MS. Projected cost comparison of trabectome, iStent, and endoscopic cyclophotocoagulation versus glaucoma medication in the Ontario Health Insurance Plan. $J$ Glaucoma. 2014;23(2):e112-8. doi:10.1097/JJG.0b013e31829d9bc7.

23. Service Ontario. Ontario drug benefit act; 2018. Available from: http://www.e-laws.gov.on.ca/html/regs/english/elaws_regs_960201_ e.htm. Accessed March 18, 2018

24. Kim YI, Kim JH, Lee TY, Lee KW. Efficacy and safety of glaucoma patients' switch from a $2 \%$ dorzolamide $/ 0.5 \%$ timolol fixed-combination brand-name drug to its generic counterpart. J Ocul Pharmacol Ther. 2015;31(6):335-339. doi:10.1089/jop.2014.0170

25. NetMBA. The product life cycle. NetMBA; 2010. Available from: http://www.netmba.com/marketing/product/lifecycle/. Accessed August 30, 2016.

26. Zhang J. AS. Market Analysis of Currently Available Prescription Drugs. Association for Business and Economics Research (ABER); 2009.

27. H. B. Benefits and limitations of product life cycle; 2016. Available from: http://www.marketing91.com/benefits-and-limitations-of-pro duct-life-cycle/. Accessed May 31, 2018.
ClinicoEconomics and Outcomes Research

\section{Publish your work in this journal}

ClinicoEconomics and Outcomes Research is an international, peerreviewed open-access journal focusing on Health Technology Assessment, Pharmacoeconomics and Outcomes Research in the areas of diagnosis, medical devices, and clinical, surgical and pharmacological intervention. The economic impact of health policy and health systems organization also constitute important areas of coverage. The manuscript management system is completely online and includes a very quick and fair peer-review system, which is all easy to use. Visit http://www.dovepress.com/testimonials.php to read real quotes from published authors. 